\title{
ASPECTOS ERGONÔMICOS E POSTURAIS EM CENTRO DE MATERIAL
}

\author{
Neusa Maria Costa Alexandre* \\ Marco Antonio Alves de Moraes ** \\ Nazira Mahayri *** \\ Sylvia Helena Ferreira da Cunha**
}

ALEXANDRE, N.M.C. et al. Aspectos ergonômicos e posturais em Centro de Material. Rev. Esc. Enf. USP. v. 26, n. 1, p. 87-94, mar. 1992.

Determinados fatores ambientais inadeqüados podem provocar lesões na coluna vertebral. Este trabalho discute certos aspectos ergônomicos e posturais específicos em Centro de Material com o objetivo de desenvolver uma consciência crítica a respeito dos efeitos do local de trabalho sobre a saúde.

UNITERMOS: Ergonomia. Postura. Centro de Material.

\section{INTRODUÇÃO}

As doenças músculo-esqueléticas são muito frequiêntes em todos os segmentos da sociedade, particularmente em trabalhadores da indústria ${ }^{12}$.

Nos Estados Unidos, a lombalgia é a segunda causa de atendimento em medicina ocupacional. Seu custo anual é estimado em 1 bilhão de dólares ${ }^{21}$, sendo que afeta 1 milhão de trabalhadores anualmente ${ }^{2}$.

Entre o pessoal de enfermagem, a lombalgia ocupacional também estendese à ampla faixa de trabalhadores na qual o risco e a frequiência são extremamente elevados ${ }^{11}$. No entanto, ao contrário do que acontece na indústria, estes estudos ainda são incipientes especialmente quanto aos aspectos epidemiológicos e ergonômicos.

Este trabalho procura elucidar determinados aspectos ergonômicos e posturais específicos em Centro de Material com o objetivo de orientar o pessoal que trabalha no setor, discutindo as possíveis alterações necessárias.

* Enfermeira - Professor Assistente do Departamento de Enfermagem da FCM da UNICAMP e do GIPEC.

* Fisioterapeuta do Centro do Saúde da Comunidade (CECOM) e do Grupo Interdisciplinar de Prevenção e Estudos de Patologia da Coluna Vertebral (GIPEC)

*** Reumatologista - Título de Especialista em Reumatologia pela Sociedade Brasileira de Reumatologia. 


\section{CONSIDERAÇÕES SOBRE ERGONOMIA}

Sendo a Ergonomia uma ciência recente, faz-se necessário algumas ponderaçōes a seu respeito.

Também conhecida nos Estados Unidos por Engenharia Humana, a Ergonomia é definida por SINGLETON"s como "uma tecnologia da concepção do trabalho baseada nas ciências biológicas humanas". Para LAVILLE" ${ }^{18}$ é "o conjunto de conhecimentos a respeito do desempenho do homem em atividade, a fim de aplicá-los à concepção das tarefas, dos instrumentos, das máquinas e dos sistemas de produção". PALMER ${ }^{23}$ já a define como "o estudo científico da relação entre o homem e seu ambiente de trabalho". Nesse sentido, o termo ambiente abrange não apenas o meio propriamente dito em que o homem trabalha, mas também os instrumentos, os métodos e a organização desse trabalho. Relacionado a tudo isso está ainda a natureza do próprio homem, o que inclui suas habilidades, capacidades e limitações.

Atualmente sabe-se que vários são os problemas decorrentes de condiçōes ergonômicas inadequadas. Entre estes, pode-se ressaltar os distúrbios da coluna vertebral que, no Brasil, ocupam uma alta prevalência entre os doenças ocupacionais, sendo a segunda causa de afastamento dos trabalhadores ao serviço e de aposentadoria requerida ao INAMPS ${ }^{17}$. Os fatores que contribuem para produzir lesões na coluna quase sempre, estāo relacionados com os elementos que compõem o trabalho, ou seja, a ferramenta, o posto, a postura, etc.

No Brasil, a Ergonomia está apenas no início, sendo que para o CEBERC ${ }^{9}$ a questão da busca de condições de trabalho mais seguras e a consequente eliminação das fontes de risco configura-se como o caminho mais viável e adequado para a aplicação da Ergonomia em nosso país.

Assim, ela fornece informações e dados que possibilitam uma análise de forma crítica das situações de trabalho, com o objetivo de reorganizá-las para que o homem possa ter um desempenho ideal com o mínimo de dispêndio energértico e de sobrecarga sobre suas estruturas como, por exemplo, a coluna vertebral.

\section{CONSIDERAÇÕES ERGONÔMICAS E POSTURAIS ESPECÍFICAS}

Como foi descrito, a Ergonomia deve ser efetivamente aplicada para identificar aspectos do trabalho que podem causar lesões na coluna vertebral.

A mobília e os equipamentos são partes importantes do ambiente de trabalho e, quando inadequadamente planejados, podem ser fatores de risco à saúde do trabalhador. Eles predispōem o corpo humano a assumir posturas que podem causar fadiga muscular a lesōes na coluna vertebral ${ }^{14}$.

Sendo assim, é de fundamental importância a identificação de possíveis fontes de riscos no ambiente de trabalho levando em consideração uma abordagem que garanta a determinação de sistemas seguros de trabalho dentro de uma estrutura ergonômica.

Com o objetivo de contribuir para a prevenção de lesões na coluna vertebral por problemas posturais em Centro de Material, o Grupo Interdisciplinar de 
Prevenção e Estudos de Patologias da Coluna Vertebral do Centro de Saúde da Comunidade da UNICAMP (GIPEC), elaborou algumas consideraçōes à partir da observação do ambiente de trabalho e das atividades desenvolvidas pelo pessoal de enfermagem deste local específico.

\subsection{TÉCNICAS ADEQUADAS DE LEVANTAMENTO, MANUSEIO E TRANSPORTE DE CARGAS}

- Respeitar os valores-limites de carga segundo o sexo, a freqüencia de levantamento e a idade

O trabalhador deve assegurar-se de que a carga está dentro de sua capacidade de erguê-la ou transportá-la. Caso contrário, obter ajuda de outras pessoas ou utilizar auxílios mecânicos ${ }^{19}$.

É importante ressaltar que a legislação brasileira sobre o levantamento e transporte de cargas é a seguinte:

* Manejo Manual de Cargas: Dispositivos Legais ${ }^{24}$.

Ergonomia - Portaria $\mathrm{n}^{\mathrm{Q}} 3.214$, de 08/06/78 NR 17.

17.1.1. Admite-se o transporte e descarga individual de peso máximo de $60 \mathrm{Kg}$.

17.1.2. O levantamento individual de $40 \mathrm{Kg}$ é o peso máximo que um empregado adulto pode levantar, ressalvadas as disposiçōes relativas ao trabalho do menor e da mulher.

* As mulheres não podem trabalhar em serviços que exijam o emprego de força munscular superior a $20 \mathrm{Kg}$, para o trabalho contínuo, e $25 \mathrm{Kg}$ para o trabalho ocasional, salvo se a tração for feita mecanicamente (CLT art. 390).

A ORGANIZACION INTERNATIONAL DEL TRABAJO22 recomenda que se limite o emprego de mulheres no transporte manual de cargas e que o peso máximo de carga que pode ser transportado por mulheres deveria ser consideravelmente inferior à carga transportada por trabalhadores do sexo masculino.

Em relação à idade, FINOCCHIARO' menciona que os discos lombares suportam pressões diferentes em função da faixa etária. Acrescenta que há um decréscimo na resistência do disco com o envelhecimento.

- Obter condições seguras do solo

Deve-se examinar o piso e a rota de transporte proposta, removendo todos os obstáculos.

- Manter o dorso retificado e os joelhos fletidos ao levantar cargas

Segundo FINOCCHIARO', a coluna vertebral deve servir de elemento de suporte e nunca como elemento de articulação. COUTO $^{6}$ argumenta que o modo mais errado de se levantar um peso é a utilização dos músculos dos dorso para essa tarefa, pois estes devem ser considerados apenas como músculos posturais. Prossegue dizendo que a musculatura dos membros inferiores é que deve fazer o esforço físico de elevação do corpo quando se está levantando um peso. 
GRANDJEAN ${ }^{10}$ ạfirma que as costas retas asseguram que as pressões nos discos intervertebrais seja uniformente distribuídos.

- Carregar a carga o mais próximo possível do corpo

Para levantar ou transportar cargas é preciso que o centro de gravidade do corpo se encontre na linha vertical que passa pelo centro de gravidade da carga. Este centro de gravidade da carga deverá encontrar-se situado sobre o interior do polígono de sustentação que é a superfície compreendida entre os pés ${ }^{19}$.

- Posicionar os pés corretamente

A posição incorreta dos pés no manejo manual de cargas pode causar lesões na coluna por produzir, muitas vezes, perda de equilíbrio. Discorrendo sobre o equilíbrio, FRACCAROLI ${ }^{8}$ assinala que este está condicionado a diversos fatores, sendo que um deles é a base. Este autor explica ainda que a estabilidade é diretamente proporcional à área da base no qual o corpo repousa. Assim, quanto mais larga for a base de apoio, maior será a estabilidade do objeto. Como os pés constituem a base de sustentação do corpo, devem ficar separados para proporcionar um aumento da base.

- Evitar movimentos de torção em torno do eixo vertical do corpo

Em operaçōes de movimento lateral um dos pés deve ser colocado na direção da carga a movimentar e o outro colocado na direção do fim do movimento lateral da carga, para evitar torção do tronco'.

- Posicionar corretamente as mãos na carga

Deve-se segurar a carga usando totalmente as mãos pois isto auxilia na manutenção do equilíbrio e evita pressões excessivas que são provocadas ao se utilizar apenas parte da mão?

\subsection{A UTILIZAÇĀO DE ARMÁRIOS}

- Evitar o estiramento da coluna

Segundo KNOPLICH ${ }^{16}$, o estiramento consiste na ampliação de um segmento da coluna às custas da musculatura que pode causar danos à esta quando é realizado com freqüência.

Este movimento é muito utilizado ao se colocar ou retirar objetos das partes altas de estantes. Para ser evitado deve-se usar um banquinho ou escadinha. No entanto, esta medida somente auxilia quando as prateleiras mais altas não são freqüêntemente usadas e quando os objetos não são muito pesados.

PALMER $^{23}$ discorrendo sobre os limites aceitáveis de alcance, menciona que estes são influenciados não apenas pelo tamanho do corpo e pelas forças a serem exercidas, mas também pela frequiência da ação. Recomenda que os objetos pesados devem ser guardados dentro de uma amplitude estreita de alturas próximas à cintura, e, que os objetos leves, devem ser amazenados a qualquer altura que se situe entre o joelho e o ombro.

Dessa forma, seria o ideal ter em mãos dados antropométricos específicos 
dos profissionais de enfermagem para que baseados nestes, se pudesse planejar o armazenamento de materiais em armários.

- Evitar a inclinação do tronco mantendo os membros inferiores estirados

Esta ação é geralmente executada ao se retirar objetos de locais mais baixos de estantes ou armários.

HEARN ${ }^{13}$ menciona que em virtude do mecanismo dos discos, é desaconselhável forçar demasiadamente a flexão das articulações da coluna ao se inclinar o tronco mantendo as pernas esticadas.

Dessa forma, deve-se evitar abaixar desnecessariamente e, recomenda-se, que ao abaixar-se, os joelhos devem ser fletidos.

\subsection{O TRABALHO EM PÉ}

- Colocar os pés alternadamente em um banquinho

O Centro de Material é um local que obriga o pessoal de enfermagem a ficar em pé por muito tempo ao lavar ou preparar materiais.

CAILLIET ${ }^{4}$ pondera que ficar em pé por tempo prolongado pode causar dor lombar e sugere que as pessoas que trabalham nesta posição devem colocar alternadamente os pés em um pequeno banco. Em uma outra publicação, este mesmo autor", apresenta a sequinte explicação: "Para uma pessoa que é obrigada a ficar em posição parcialmente inclinada durante muitas horas por dia, como um barbeiro, dentista ou dona de casa, que trabalha debruçada sobre uma pia ou um berço, haverá menos fadiga se as costas ficarem retas e o centro de gravidade for mantido sobre os quadris e os pés. Fletir um quadril ajudará a assumir a postura das costas planas, pois eliminará a tração do flexor do quadril sobre a coluna lombar. Portanto, colocando um pé sobre um banquinho com o quadril e o joelho fletidos permitirá uma posição vertical com uma lordose menor'.

- Utilizar uma altura de bancada de trabalho adequada

Ao se discutir o trabalho na posição em pé, é também importante ressaltar aspectos da altura da superficíe da bancada. Nos ambientes de trabalho existem certos fatores de risco como, por exemplo, pias e bancadas com alturas muito baixas que impõem uma postura inadequada.

Alguns autores ${ }^{53}{ }^{13.16}$ recomendam que quando o indivíduo trabalha em pé, a bancada deve ser construída de tal modo que sua superfície deva chegar pelo menos à altura dos cotovelos.

\subsection{O TRABALHO SENTADO}

No Centro de Material o pessoal da enfermagem permanece sentado por tempo prolongado ao realizar tarefas de inspeção, lavagem, secagem e empacotamento de materiais.

NACHEMSON e ELFSTROM ${ }^{20}$, em seus estudos sobre a pressão intradiscal, afirmam que a postura sentada, comparando com a deitada e em pé, é a 
mais danosa para a coluna e que a intensidade de pressão aumenta de 3 a 4 vezes se o corpo estiver fletido para frente.

Para KNOPLICH${ }^{16}$, além da pressão intradiscal, outros farores devem ser levados em conta quando se usa a postura sentada no trabalho, tais como: a tensão-músculo-ligamentar; o movimento de torção do tronco e o trabalho repetitivo.

Entretanto, conforme IIDA e WIERZZBICKI ${ }^{15}$ existe uma tendência atual de se projetar máquinas e equipamentos que possam ser operados por um homem sentado.

FINOCCHIARO ${ }^{7}$ afirma que é sempre preferível o trabalho na posição sentada em relação a em pé. $O$ ideal inclusive, para ele, é o trabalho na posição sentada intercalado comn breves operações na posição em pé.

\section{- Adaptar a altura da bancada ou mesa à altura do assento}

Para FINOCCIARO', a posição sentada é ideal para o trabalho desde que a cadeira e a bancada tenham características adequadas de projeto, tanto individualmente quanto no seu conjunto.

Se um trabalho sentado tiver de ser efetuado diante de uma mesa ou bancada, seria recomendável o uso de uma cadeira giratória, de encosto e assento reguláveis, firme e de altura compatível com a mesa e adequada para que os pés estejam sempre bem apoiados no chão, nunca pendurados. $O$ encosto deve possuir apoio para a região lombar alta e a mesa deve estar na altura dos cotovelos. $O$ assento deve ser profundo, deixando aproximadamente $5 \mathrm{~cm}$ entre a cadeira e a face posterior do joelho's.

Muitos autores ${ }^{7,15,16,26}$ sugerem que se utilize uma banqueta para apoiar os pés, de maneira que permita uma flexão do joelho em ângulo reto, evitando uma pressão na região poplitea.

- Não utilizar banquinhos

Não se recomenda o uso dos bancos para o trabalho sentado.

IIDA e WIERZZBICKI's salientam que a postura estática provoca a contração constante de grupos musculares, o que leva a uma deficiência na irrigação local, sobrevindo logo a fadiga, que se converte em sensação dolorosa, tornando-se insuportável em pouco tempo. Afirmam também que quando na posição sentada, a fadiga dos músculos que sustentam o tronco ereto pode ser reduzida pelo uso de uma apoio.

KNOPLICH ${ }^{16}$ cita que a postura sentada sem o apoio das costas aumenta a solicitação da musculatura dorsal e a pressāo intradiscal. Sugere, entāo, que se utilize uma cadeira com encosto.

- Variar as posições

Deve-se evitar permanecer sentado por tempo prolongado em uma mesma posição. Embora existam posturas mais indicadas para as diversas situações, sabe-se que a permanêmncia estática constante sobrecarrega o sistema músculo-ligamentar, podendo ocorrer a fadiga. Portanto, é indicado que se varie com freqüência as posições ao se realizar tarefas e que se dê um intervalo de descanso entre os períodos de trabalho, numa proporção de $1: 2^{1, ~ ?}$. 


\subsection{A UTILIZAÇÃO DE CARRINHOS}

As operaçōes de empurrar e puxar carrinhos no Centro de Material são bastantes comuns com a finalidade de transportar objetos.

- Transportar cargas em carrinhos de forma adequada

Para FINOCCIARO', nas atividades de transporte de cargas em carrinhos, sempre que possível, deve-se preferir empurrar a puxar. Nessas condições, a sobrecarga cai sobre os membros inferiores que impulsionam o movimento, evitando assim, o esforço na coluna vertebral.

A ação de empurrar dever ser rea;izada sobre o extremo do carrinho onde há a roda pivolante. É necessário que se coloque um pé a frente do outro, dobrese os joelhos, mantenha-se a coluna ereta e se posicione os braços retos na traseira do carrinho em uma altura correspondente à altura da cintura. Deve-se evitar a rotação do tronco com os pés juntos, ao realizar o giro do carrinho.

\section{CONSIDERAÇÕES FINAIS}

Os componentes do ambiente de trabalho nem sempre são analisados em relação aos seus efeitos na saúde do trabalhador.

É de fundamental importância que o ambiente nos hospitais levem em conta os fatores humanos da equipe de enfermagem e dos pacientes. Os equipamentos e espaço físico hospitalares precisam ser concebidos segundo as características do pessoal que os utiliza. Dessa forma, o ideal seria ter em mãos dados antropométricos e biomecânicos dos profissionais de enfermagem.

Espera-se que este trabalho, auxilie no desenvolvimento de uma consciência crítica em relação aos efeitos do local de trabalho sobre a saúde da equipe de enfermagem e favoreça a elaboração de novos trabalhos sobre este tema.

ALEXANDRE, N.M.C. et al. Ergonomic and postural aspects in a central supply unit. Rev. Esc. Enf. USP, v. 26, n. 1, p. 87-94, mar. 1992.

Unsutable environmental factors can lead to back injuries. In order to develop a critical thinking about the workplace effects on human health, this paper discuss ergonomic and postural aspects in a Central Supply Unit.

UNITERMS: Ergonomics. Posture. Central Supply Unit.

\section{REFERÊNCIAS BIBLIOGRÁFICAS}

1. ASTRAND, P.O.; RODAHL, K. Tratado de filosofia do exercício 2. ed. Rio de Janeiro, Interamericana, 1977

2. BACK injuries assocated with lifting. Washington, U.S. Department of Labor. 1982.

3. CAILLIET, R. Síndrome dolorosas: lombalgias. São Paulo, Manole 1979.

4. Compreenda sua dor de coluna São Paulo, Manole, 1985. 
5. CHAFFIN, D.B. Manual materials handling and the biomechanical basis for prevention of lowback pain in industry - an oveview. Am. Ind. Hyg. Assoc. J., v. 48, n. 12, p. 989-96, 1987.

6. COUTO, H.A. Fisiologia do trabalbo aplicada. Belo Horizonte, Ibérica, 1978.

7. FINOCCHIARO, J. et al. Manual de prevenção das lombalgias. São Paulo, Lex, 1978.

8. FRACCAROLI, J.L. Biomecânica. Rio de Janeiro, Cultura Médica, 1981.

9. FUNDAÇĀO GETÚLIO VARGAS. INSTITUTO SUPERIOR DE ESTUDOS E PESQUISAS PSICOSOCIAIS. Centro Brasileiro de Ergonomia e Cibernética. Análise sociotecnológica. Rio de Janeiro 1982

10. GRANDJEAN, E. Fitting the task to the man: an ergonomic approach. 3. ed. London, Taylor \& Francis, 1981

11. HARBER, P. et al. Occupational low-back pain in hospital nurses. J. Occup. Med., v. 27, n. 7, p. 518-24, 1985.

12. HARBER, P.; SOOHOO, K. Static ergonomic strenght testing in evaluating occupational back pain. J. Occup. Med., v. 26, p. 877, 1984.

13. HEARN, E.L. Você é tão jovem quanto a sua espinha. 10. ed. São Paulo, Pioneira, 1985.

14. HENIFIN, M.S. Designing the workplace for health and safety: biomechanical considerations. Occup. Health Nurs., v. 30, n. 10, p. 22-6, 1982.

15. IIDA, I,; WIERZZBICKI. J.A.J. Ergonomia. 3. ed. São Bernardo do Campo, Ed. Ivan Rossi, 1978

16. KNOPLICH, J. Enfermidades da coluna vertebral. 2. ed. São Paulo, Panamed Editorial, 1986.

17.

Agressōes posturais da profissāo de desenhista. Rev. Bras. Saúde Ocup., v. 15 , n. 57 , p. 55-8, 1987.

18. LAVILLE,A. Ergonomia. São Paulo, E.P.U., EDUSP, 1977.

19. MOURA, R.A. Segurança na movimentação de materiais. São Bernardo do Campo, Ivan Rossi Ed., 1978.

20. NACHEMSON, A.; ELFSTROM, G. Intravital dynamic pressure measurments in lumbar disc. Scand. J. Rehab. Med, v.1, p. 1-40, 1970. Supplement 2.

21. NATIONAL INSTITUTE FOR OCCUPATIONAL SAFETY AND HEALTH. Work practices guide for manual lifting. Washington, Departament of Health and Human Services, 1981

22. ORGANIZACION INTERNATIONAL DEL TRABAJO. Peso máximo de las cargas que puedem ser transportadas por um trabajador. Informe v. 6, n. 2, p.56-63, 1967.

23. PALMER, C. Ergonomia. Rio de Janeiro, Ed. Fundaçāo Getúlio Vargas, 1976.

24. SEGURANÇA e medicina do trabalho. 9. ed., São Paulo, Atlas, 1985. (Manuais de Legislaçāo Atlas, 16).

25. SINGLETON, W.T. Introduction to ergonomics. Geneva, World Health Organization, 1972.

26. VILADOT, R. et al. Coluna vertebral - ortese e prótese do aparelho locomotor. São Paulo, Ed. Santos, 1989. 